\title{
Comment
}

\section{Creative economics for a creative world: a comment}

\author{
DAVID COLANDER* \\ Middlebury College, Middlebury, VT, USA
}

\begin{abstract}
Critics of mainstream economics often argue that the mainstream does not recognize that the economy is dynamic, creative and evolving, and they base their criticism of it for its failure to recognize that. This paper argues that the mainstream does recognize that the economy is evolving, and changes its methods as new analytic technologies and computational methods develop. The paper suggests that a narrower critique of the mainstream is appropriate: It attempts to be too scientific, following a scientific rather than an engineering methodology. Thinking of applied economic policy as engineering, not science opens up new avenues of research, and will allow it be better deal with our complex world.
\end{abstract}

\section{Introduction}

I, and, I suspect, just about any other reasonable economist (interpret economist who understands that the economy is a complex evolving system) agree with almost the entirety of Koppl et al's "Economics for a Creative World." (Koppl et al, 2014) Their conclusions-we should have a more skeptical attitude toward economic experts; the tools of high theory should continue to evolve in the direction taken by complexity theory; computation will become more important; and we cannot underestimate the importance of institutions and institutional change, economic history, and applied economics-are reasonable ones that are, or at least should be, shared by all reasonable economists.

\section{The "Tell Me Something I don't Already Know" Response}

Despite, or perhaps because of reasonable mainstream economists' agreement with the paper's arguments, I suspect that the paper will not succeed in its goal of "providing a helpful prolegomena" by "promoting a larger discussion within the economics profession". I suspect that the reasonable mainstream will respond to it with their standard yawn, and their pat "Tell me something I didn't already know" response to almost any criticism.

*Email: author colander@middlebury.edu 
Koppl's et al's response to that "yawn" will likely be: "If you already knew it, why don't you change what you do?"

To which the reasonable mainstream economist will respond "The mainstream is doing quite well, thank you; that success suggests that there is no need for imposed drastic change such as suggested by Koppl et al. and other critics. We already have a skeptical attitude toward experts; tools of high theory are evolving; computation is becoming more important; and we have never underestimated the importance of institutions and institutional change. People outside economics may not recognize this, but good economists do, and incorporate it in their policy advice."

Koppl's et al's response to that will likely be: "Are you kidding us-think of all the work focusing on abstract general equilibrium theory, the lack of focus on multiple equilibrium models, the DSGE modeling in macro, the difficulty of publishing an agent based model paper, and the myriad models that deviate significantly from reality but are worked on by mainstream economists. The searching for the keys under the lamppost joke about economists didn't arise from nowhere."

To which the reasonable mainstream economist will respond: "That's the way science works-slowly, precisely, maintaining rigor by making sure that we have dotted all i's and crossed all t's before we integrate a new approach or idea into our scientific theory. We are scientists: What we work on is what we can formally shed light on. We recognize that the realm of economics lies in biology, not mechanics, and have since, at least, the time of Alfred Marshall. But to maintain scientific rigor, mechanical models were, and in many cases still are, the best we can do. The relevant question is: How can we best add to our scientific understanding, and our methodology reflects that. Mechanical equilibrium models were never ends in themselves; they were always paths to understanding dynamics. Formal dynamics, into which complexity throws us headlong, is hard—really hard—and we had to start somewhere. Our equilibrium models give us a formal rigorous structure to use as a basis for our dynamic considerations."

\section{Giving the reasonable mainstream its due}

I offer this give and take because I think it goes to the heart of Koppl et al's argument that "if we live in a creative world, it may be time to reconsider our methods, our theory, and the role of economists in a democratic world." While I agree with the sentiment behind that argument, I also believe that it will likely be misinterpreted by the reasonable mainstream. It seems to suggest that mainstream economics is not an economics for a creative world, and that the problem with mainstream economics is that it doesn't recognize that the economy is a complex system. That isn't the way the reasonable mainstream sees it, nor is it the way I see it. I see the reasonable mainstream as recognizing 
that the economy is a complex system, but as being hesitant to deal with the complexity until they have the tools to handle complexity formally. The issue at debate should be: What is the best research path to follow in studying a complex evolving economy, not: Is the economy is a complex evolving economy?

What I am saying is that, to avoid misinterpretation, criticisms of mainstream economics should best begin with an acceptance that mainstream economists: (1) believe the economy is an evolving complex system; (2) believe that it is always time to reconsider methods; and (3) change their methods where they see gains to be made. I dealt with (1) above, so let me now turn to (2) and (3).

\section{The problem with mainstream methodology}

Methodology is not a topic of mainstream discussion, but that does not mean that mainstream methodology is rigid and fixed. Methods change in economics from the bottom up, not from the top down. This means that the meso level methodology that Koppl et al. focus on gets almost no discussion within the mainstream. The aggregate mainstream methodology is the composite of the methods used by mainstream economists; it is not something chosen top down by the "profession." Mainstream methodology evolves as researchers using new methods are successful, and others follow.

What has fueled, and will fuel in the future, the movement to dynamics and complexity economics in the mainstream has been the development of new and better analytic, experimental, and computational tools. Because those tools have changed, applied micro has changed enormously-it is much more data driven-computation and data analysis more and more is dominating theory; modern applied microeconomics is a blend of natural, lab, and field experiments. Micro theory has also changed in response to these changing tools-behavioral economics is well integrated into the discussion, and evidence-based policy analysis has become the scientific norm. Rationality is no longer assumed; it is empirically determined.

In macro, yes, there was likely an overreaction to the institutionally embedded mainstream neoKeynesian synthesis model that purported to be a general theory, but was actually a heuristic build on a variety of inconsistent ad hoc elements that couldn't even be logically specified in a general equilibrium model on the agent level. As a scientific theory, the neo-Keynesian synthesis failed. To get a scientific micro-grounded macro theory the mainstream had to develop a new general theory of macroeconomics. It did that. True, the initial macro theory the profession developed was way too simple. But it has evolved-from New Classical, to real business cycles, to DSGE modeling with learning, multiple equilibria, and model uncertainty. It will continue to evolve, and the work done so far is seen by the reasonable mainstream as a scientific stepping stone to the complexity approach to macro theory. Indeed, many of the of the complexity 
researchers, such as Leigh Tesfatsion and Blake LeBaron, come from New Classical programs.

\section{A narrower critique of economics: scientific rigor as a constraint on creativity}

The above arguments that mainstream economics recognizes that the economy is a complex evolving system, and has a changing methodology does not mean that I think the mainstream is doing a good job in integrating complexity thinking into its thinking. It isn't, and its methodology is changing far too slowly. However, the reason isn't that the mainstream doesn't have to right goals; the reason is that it isn't following the best path. It requires researchers to deal with that complexity in a too formally scientific manner. That prevents the mainstream from exploring many complexity issues that, at their current stage of development, can be loosely, but not formally, formulated. The problem is most serious in the mainstream's consideration of policy.

The reasonable mainstream's commitment to a formal scientific methodology requires any theoretical considerations to have all i's dotted and t's crossed before these policies become part of the academic discourse. For what might be called high science, where the goal is understanding for the sake of understanding, that approach may be fine. But most work and models in economics are not high science; they are what might be better called low, or applied, science. By that I mean that the models and theory are primarily designed to shed light on policy, not to increase our understanding for the sake of understanding. The mainstream's mistake is that they combine high and low science together and use scientific methodology for both. ${ }^{1}$

Policy theorizing should not be thought of as applied science and should not be governed by scientific methodology. It should be governed by an engineering methodology, which has been spelled out by Billy Vaughn Koen (2003). Koen defines the engineering method as "the strategy for causing the best change in a poorly understood or uncertain situation within the available resources." $\mathrm{He}$ argues that this definition is operationally equivalent to a second definition-use the best available engineering heuristics to solve problems. Heuristics includes all theories and models, and any other aid, such as intuition, experience, and

1 My methodological critique of the profession is similar to Deirdre McCloskey's (McCloskey, 1986) and is derivative of it, since her work was important in shaping my views. Where my critique differs from hers is in emphasis. I emphasize the need to distinguish between the art and science of economics; she emphasizes the need to distinguish between mathematics and science. Specifically, she criticizes the profession for following a modernist, logical positivist methodology: I don't. I criticize the profession for not following following its Millian/JN Keynesian roots, which preceded logical positivism and modernism. (Colander and Su, forthcoming) This results in different critiques of the profession's methodology. She criticizes the methodology of the science of economics. My critique does not; it only argues that the applied part of economics should not be seen as applied science; it should be seen as engineering. 
expert knowledge that may usefully lead to a solution. Using an engineering methodology, nothing is off the table.

This engineering methodology is quite different from the applied science methodology that mainstream applied economists follow. A scientific methodology is focused on understanding for the sake of understanding. Its goal is to find the "Truth"; an applied scientific methodology is focused on applying the truths one has found in science to real-world problems. Scientific knowledge constrains applied policy thinking. Since an engineer is interested not in truth but in solving problems; scientific knowledge does not constrain an engineer. The approach an engineer uses may be based on science, but it need not be. NeoKeynesian macro was lousy science, but was very likely good engineering; it provided a heuristic guide for policy when the scientific theory was unknown.

An engineer makes no claim for the heuristic he is using being the truth, or even being a correct representation of the problem. Truth is not an issue of importance to an engineer except as it relates to the solution of the problem at hand. Engineering is all about heuristics. Heuristic knowledge may include applied scientific knowledge, which has been developed using a scientific heuristic and which meets generally accepted scientific criteria. But it includes much more. Heuristic knowledge also includes a variety of sources of understanding that experience has shown to be useful.

Thinking of applied economic policy as engineering, not science, opens up new avenues of policy considerations that would allow complexity to enter the policy discussion long before the science of complexity is ready for prime time. It would encourage economic discourse to include much more daydreaming, speculation and playing around with ideas. The assumptions that currently guide policy-exogenous tastes, no interdependent utility functions, no contagion, no evolutionary institutions, extreme rationality-assumptions that were only used because they led to tractable models-would no longer hold the power that they currently do. Eliminating these arbitrary assumptions would change policy analysis enormously, and would allow much more consideration of complexity elements of the economy. A much wider set of policy considerations, which I have spelled out in Colander and Kupers (2014), would come into play.

I suspect that the only way to get the mainstream profession to change is indirectly through institutional changes. An institutional lock-in has occurred that has tied mainstream economics theorizing about policy with formal scientific models. For science that may be a useful tie-in, but for policy and engineering, it is not. Creative theorizing in engineering generally precedes formal scientific theorizing. It is time to start using creative theorizing in studying our creative world.

\section{References}

Colander, D. and H.-C. Su (forthcoming), 'Making Sense of Economists' Positive-Normative Distinction', Journal of Economic Methodology. 
Colander, D. and R. Kupers (2104), Complexity and the Art of Public Policy: Solving Society's Problems from the Bottom Up, Princeton: Princeton University Press.

Koen, B. V. (2003), Discussion of the Method: Conducting the Engineer's Approach to Problem Solving, Oxford: Oxford University Press.

Koppl, R., K. Stuart, F. Teppo and L. Giuseppe (2014), 'Economics for a Creative World', Journal of Institutional Economics, published online. DOI: 10.1017/ S1744137414000150.

McCloskey, D. (1986), The Rhetoric of Economics, Madison: University of Wisconsin Press. 